\title{
Resume Driving After a Refueling Pit Stop
}

\author{
Yasushi Oginosawa, MD; Haruhiko Abe, MD; \\ Ritsuko Kohno, MD; Hitoshi Minamiguchi, MD
}

$\mathbf{T}$ he indications for implantation of cardioverter defibrillators (ICD) have broadened from secondary prevention for survivors of sudden cardiac death to primary prevention for high-risk conditions, such as Brugada syndrome, depressed left ventricular ejection fraction and hypertrophic cardiomyopathy. ${ }^{1-3}$ Furthermore, the indications for cardiac resynchronization therapy with defibrillator (CRTD) are soon likely to include New York Heart Association class II heart failure. ${ }^{4-6}$ With the increasing rate of both implantation of ICD and CRT-D because of the broadening of indications and the inclusion of patients with a long life expectancy, the number of generator replacements is growing, despite longer battery longevity.

\section{Article p2301}

Driving a vehicle is an important determinant of a person's range of activity and quality of life. On the other hand, lifethreatening tachyarrhythmias occur unpredictably, usually disabling the patient within a few seconds. In addition, ICD shocks delivered while driving may cause traffic accidents and injuries to the driver, the passengers and other motorists or pedestrians. Therefore, driving restrictions that are imposed must balance the issues of patient rights and public safety.

In 2003, a Joint Committee of the Japanese Circulation Society, Japanese Heart Rhythm Society and Japanese Association for Thoracic Surgery published a statement regarding driving restrictions for patients suffering from syncope caused by a cardiac arrhythmia, ${ }^{7}$ recommending that patients undergoing ICD replacement without the addition or repositioning of a lead be prohibited from driving for 1-6 months, depend- ing on the physician's judgment. These statements raised several issues. First, patients who had been allowed to drive before ICD replacement must quit for 1-6 months after the procedure. Second, several investigators have reported poor patient compliance with the driving limitations imposed by healthcare professionals. ${ }^{8-10}$ The longer prohibition might make it even harder to follow the rules. Third, the basis for the length of the prohibition period is not clear and varies among physicians. These variations might provoke a sense of inequality among patients. On the other hand, this statement has successfully protected the public since, as to the best of our knowledge no traffic accidents caused by an ICD shock or by syncope because of a ventricular tachyarrhythmia after generator exchange, have been reported. Therefore, before revising the statement with a view to improving the patients' quality-of-life, and to gain the acceptance by the public and the authorities, scientific evidence should be offered that a shorter prohibition period will not jeopardize traffic safety.

In their study published in this issue of the Journal, Kawata et $\mathrm{a}^{11}$ measured the incidence of ICD therapy before and after the procedure in 128 patients who underwent ICD generator replacement $(72 \%$ implanted for secondary prevention) without replacement or implantation of a new lead system. They found (1) no difference in the delivery of ICD therapy between the 3 and 6 months before vs after ICD replacement, (2) delivery of therapy after device replacement in $8.6 \%$ of patients who were driving legally according to the Japanese guidelines at 1 year, associated with a low annual risk of death or injury to others, and (3) a single case of inappropriate therapy related to a change in the treatment algorithm, immediately after discharge of the patient from

\begin{tabular}{|c|c|c|c|c|}
\hline & Japan 2010 & Japan 2003 & Europe 2009 & United States 2007 \\
\hline ICD implantation for secondary prevention & 6 months & 6 months & 3 months & 6 months \\
\hline ICD implantation for primary prevention & 30 days & 6 months & 4 weeks & $\begin{array}{l}\text { Recovery from } \\
\text { operation (at least } \\
1 \text { week) }\end{array}$ \\
\hline After ICD therapy & 12 months & 12 months & 3 months & 6 months \\
\hline After replacement of the ICD & 7 days & $\begin{array}{l}1-6 \text { months } \\
\text { (depending } \\
\text { on physician) }\end{array}$ & 7 days & No specific comment \\
\hline After replacement of the lead & 30 days & 6 months & 4 weeks & No specific comment \\
\hline
\end{tabular}

The opinions expressed in this article are not necessarily those of the editors or of the Japanese Circulation Society.

Received September 6, 2010; accepted September 6, 2010; released online October 16, 2010

Division of Cardiology (Y.O., H.A., R.K., H.M.), Department of Heart Rhythm Management (H.A.), University of Occupational and Environmental Health, Kitakyushu, Japan

Mailing address: Haruhiko Abe, MD, Department of Heart Rhythm Management, University of Occupational and Environmental Health,

1-1 Iseigaoka, Yahatanishi-ku, Kitakyushu 807-8555, Japan. E-mail: haru-abe@med.uoeh-u.ac.jp

ISSN-1346-9843 doi:10.1253/circj.CJ-10-0900

All rights are reserved to the Japanese Circulation Society. For permissions, please e-mail: cj@j-circ.or.jp 
the hospital. The authors conclude that ICD replacement without a change in lead or algorithm has no effect on the delivery of therapy, and recommended 1 week of driving prohibition after the procedure.

In 2010, the statement by the Japanese National Police Agency pertaining to driving restriction for patients with syncope related to cardiac arrhythmias was upgraded. ${ }^{12}$ The key points of the update were (a) a risk stratification based on primary vs secondary prevention, and (b) a shortening of the duration of driving restrictions. Patients legally eligible to drive according to the Japanese guidelines before ICD replacement can resume driving after a 7-day period of observation. If a lead has been replaced or implanted, the observation period should be extended to 30 days. Table compares the 2010 and 2003 Japanese, and current European ${ }^{13}$ and American, ${ }^{14}$ statements regarding individual driving restrictions imposed after ICD/CRT-D implantation and replacement. Except for the period following ICD therapy, the criteria and duration of prohibition in Japan are nearly the same as in Europe. Besides improving the patients' quality-of-life without jeopardizing public safety, these guidelines may facilitate the counseling by healthcare professionals, as well as the adherence to the rules by the patients.

\section{Disclosures}

Grant: none. Contract and financial support: none. Relationship with industry: none.

\section{References}

1. Moss AJ, Zareba W, Hall WJ, Klein H, Wilber DJ, Cannom DS, et al, Multicenter Automatic Defibrillator Implantation Trial II Investigators. Prophylactic implantation of defibrillator in patients with myocardial infarction and reduced ejection fraction. $N$ Engl J Med 2002; 346: 877-883.

2. Bardy GH, Lee KL, Mark DB, Poole JE, Packer DL, Boineau R, et al, Sudden Cardiac Death in Heart Failure Trial (SCD-HeFT) Investigators. Amiodarone or an implantable cardioverter-defibrillator for congestive heart failure. N Engl J Med 2005; 352: $225-$ 237.

3. Moss AJ. What we have learned from the family of multicenter automatic defibrillator implantation trials. Circ J 2010; 74: 1038 1041.

4. Linde C, Abraham WT, Gold MR, St John Sutton M, Ghio S,
Daubert C, REVERSE (REsynchronization reVErses Remodeling in Systolic left vEntricular dysfunction) Study Group. Randomized trial of cardiac resynchronization in mildly symptomatic heart failure patients and in asymptomatic patients with left ventricular dysfunction and previous heart failure symptoms. J Am Coll Cardiol 2008; 52: $1834-1843$.

5. Moss AJ, Hall WJ, Cannom DS, Klein H, Brown MW, Daubert JP, et al, MADIT-CRT Trial Investigators. Cardiac-resynchronization therapy for the prevention of heart-failure events. $N$ Engl J Med 2009; 361: 1329-1338.

6. Shimizu A. Cardiac resynchronization therapy with and without implantable cardioverter-defibrillator. Circ J 2009; 73: A-29-A-35.

7. Aizawa Y, Ikeguchi S, Okabe F, Ogawa S, Kasanuki S, Katoh T, et al. Joint committee statement about driving restriction in patients with syncope related to cardiac arrhythmia. J Arrhythmia 2003; 19: 502-512 (in Japanese).

8. Albert CM, Rosenthal L, Calkins H, Steinberg JS, Ruskin JN, Wang $\mathrm{P}$, et al, TOVA Investigators. Driving and implantable cardioverterdefibrillator shocks for ventricular arrhythmias: Results from the TOVA study. J Am Coll Cardiol 2007; 50: 2233-2240.

9. Conti JB, Woodard DA, Tucker KJ, Bryant B, King LC, Curtis AB. Modification of patient driving behavior after implantation of a cardioverter defibrillator. Pacing Clin Electrophysiol 1997; 20: 2200-2204.

10. Maas R, Ventura R, Kretzschmar C, Aydin A, Schuchert A. Syncope, driving recommendations, and clinical reality: Survey of patients. BMJ 2003; 326: 21.

11. Kawata H, Noda T, Kurita T, Yamagata K, Yamada Y, Okamura H, et al. Clinical effect of implantable cardioverter defibrillator replacements: When should you resume driving after an implantable cardioverter defibrillator replacement? Circ J 2010; 74: 2301-2307.

12. The National Police Agency. A revision to the Japanese Road Traffic Act. 2010 June: http://www.npa.go.jp/pdc/notification/koutuu/ menkyo/menkyo20100702.pdf (in Japanese) (accessed September 2010).

13. Vijgen J, Botto G, Camm J, Hoijer CJ, Jung W, Le Heuzey JY, et al. Consensus statement of the European Heart Rhythm Association: Updated recommendations for driving by patients with implantable cardioverter defibrillators. Europace 2009; 11: 1097-1107.

14. Epstein AE, Baessler CA, Curtis AB, Estes NA 3rd, Gersh BJ, Grubb B, et al, American Heart Association; Heart Rhythm Society. Addendum to "Personal and Public Safety Issues Related to Arrhythmias That May Affect Consciousness: Implications for Regulation and Physician Recommendations. A medical/scientific statement from the American Heart Association and the North American Society of Pacing and Electrophysiology": Public safety issues in patients with implantable defibrillators: A Scientific statement from the American Heart Association and the Heart Rhythm Society. Heart Rhythm 2007; 4: 386-393. 